\title{
VARIABILIDADE QUANTITATIVA DE POPULAÇÃO MICROBIANA ASSOCIADA ÀS CONDIÇÕES MICROCLIMÁTICAS OBSERVADAS EM SOLO DE FLORESTA TROPICAL ÚMIDA
}

\author{
HERNANI JOSÉ BRAZÃO RODRIGUES ${ }^{1}$, LEONARDO DEANE DE ABREU SÁ ${ }^{2}$, MARIA DE \\ LOURDES PINHEIRO RUIVO ${ }^{3}$, ANTÔNIO CARLOS LÔLA DA COSTA ${ }^{1}$, ROMMEL BENICIO DA \\ SILVA $^{4}$, QUÊZIA LEANDRO DE MOURA ${ }^{5}$, IVAN FIUZA DE MELLO ${ }^{6}$ \\ ${ }^{1}$ Universidade Federal do Pará (UFPA), Belém, PA, Brasil \\ ${ }^{2}$ Instituto de Pesquisa Espacial (INPE), Belém, PA, Brasil \\ ${ }^{3}$ Museu Paraense Emílio Goeldi (MPEG), Belém, PA, Brasil \\ ${ }^{4}$ Universidade de São Paulo (USP), São Paulo, SP, Brasil \\ ${ }^{5}$ Universidade Federal do Pará (UFPA), Programa de Pós-Graduação em Ciências Ambientais (Mestrado), \\ Belém, PA, Brasil \\ ${ }^{6}$ Universidade Federal do Pará (UFPA), Faculdade de Meteorologia (Graduação), Belém, PA, Brasil
}

hernani@ufpa.br, 1dsa@inpe.gov.br, ruivo@museu-goeldi.br; rbcsilva@yahoo.com.br, queziamoura@, hotmail.com,imello11@hotmail.com

Recebido Maio de 2010 - Aceito Junho de 2011

\begin{abstract}
RESUMO
Este estudo é uma proposta de contribuição científica ao entendimento das inter-relações entre densidade de populações de microorganismos de solo, associadas à variabilidade microclimática sazonal em floresta tropical úmida, considerando também estudo de caso de evento extremo. Alguns organismos vivos, especialmente microorganismos de solo, são muito sensíveis às pequenas variações microclimáticas (luminosidade, temperatura, umidade do solo, vento, calor sensível, calor latente, etc. Seguramente estes fatores condicionantes são importantes para o entendimento da distribuição espacial destes seres vivos em ecossistemas naturais, habitados por uma enorme variedade de microorganismos (fungos e bactérias). Estes foram estudados quanto sua distribuição e densidade, utilizando a técnica "Pour Plate" de contagem em placas de "Petri" seguindo a metodologia utilizada por De-Polli e Guerra, descrita por Clark. O estudo foi realizado em duas áreas experimentais, PPBio (área de floresta densa natural) e ESECAFLOR (área de um hectare coberta para simulação de seca prolongada) em Caxiuanã-PA, com medidas contínuas de variáveis microclimáticas térmicas, úmidas e precipitações, além da avaliação de padrões de distribuição espacial e temporal da abundância e riqueza das espécies, para estabelecer um sistema de monitoramento de fungos e bactérias de solo associado à variabilidade climática na floresta nacional de Caxiuanã. As áreas experimentais são predominantemente de Yellow Latossolo. As análises microbiológicas mostraram que fungos desenvolveram-se melhor em época seca e bactérias na época chuvosa. Suas populações diminuem com a profundidade, exceto em ambiente alterado. As correlações de variações sazonais entre populações de fungos e bactérias e as variáveis temperatura e umidade do solo, se estabeleceram satisfatoriamente para qualquer época do ano em ambos os sítios estudados.
\end{abstract}

Palavras- Chave: Microorganismos, Latossolo Amarelo, Floresta, Microclima

ABSTRACT: QUANTITATIVE MICROBIAL POPULATION VARIABILITY ASSOCIATED
WITH THE MICROCLIMATE CONDITIONS OBSERVED IN TROPICAL RAINFOREST SOIL.
This study is a proposal for a scientific contribution to the understanding of the interrelationships
between density population of soil microorganisms associated with seasonal microclimatic variability
in tropical rainforest, also considering a case study of extreme event. Some organisms, especially 
soil microorganisms are very sensitive to small variations in microclimate (sun light, temperature, soil moisture, wind, sensible heat, latent heat, etc). Surely these conditioning factors are important for understanding the spatial distribution of these living things in natural ecosystems, inhabited by a variety of microorganisms (mushroom and bacteria) that were studied for their distribution and density, using the technique of "Pour Plate" count of "Petri plates" following the methodology utilized for De-Polli and Guerra, described by Clark. This study was conducted in two experimental areas PPBio (natural rainforest area) and ESECAFLOR (one acre covered area to simulate drought) in Caxiuanã-PA, with continuous measurements of microclimatic variables such as temperature, humidity and rainfall, and the evaluation of spatial and temporal distribution patterns of the species abundance and richness, to establish a monitoring procedure of soil fungi and bacteria associated with climate variability in the national forest Caxiuanã. The experimental areas are predominantly Yellow Latossol soils. Microbiological analysis showed that fungi developed better during the dry season and bacteria during rainy season, and their populations decrease with depth, except in a changed environment. Correlation values between seasonal variation of fungi and bacteria population and varying temperature and soil humidity were satisfactorily for any season in both sites.

Keywords: Microorganisms, Yelow Latossol, Forest, Microclimate

\section{INTRODUÇÃO}

A compreensão da microclimatologia associada à biomassa microbiana do solo, é essencial para o entendimento de variações quantitativas nas populações de microorganismos em escala sazonal, e de grande importância para o estabelecimento de espécies e manutenção da microfauna de solo no ecossistema. A biomassa microbiana do solo, composta especialmente por fungos, bactérias e microfauna, é responsável pela decomposição de resíduos orgânicos depositados pela vegetação no solo (Wardle e Hungria, 1994, Chapin et al., 2002; Moreira e Siqueira, 2002).

Segundo Souto et al. (2008) entre os componentes da biota do solo, as bactérias e os fungos detém altos valores de biomassa e metabolismo respiratório, além de exercerem alta contribuição no processo de decomposição da matéria orgânica, ao passo que uma fauna variada desses dois grupos permite a degradação total de restos de plantas e animais. Esta população controla muitos processos vitais e de reciclagem de nutrientes em ecossistemas florestais, contudo, pouco se sabe a respeito da forma como essas espécies de microorganismos vivos respondem às variações climáticas locais, como também são poucos os conhecimentos dos padrões de variabilidade espacial do microclima dentro de floresta primária tropical.

A variabilidade espacial leva em consideração fatores tais como topografia, proximidade de massas de água, ocorrência de clareiras, dentre outros, os quais são importantes na adequação microclimática. Portanto, as atividades dos diversos grupos orgânicos de solo, bem como, os mecanismos de sobrevivência encontrados pelos mesmos, estão interligadas com condições ambientais, ou seja, a condições de conforto ambiental favoráveis para a manutenção e permanência desses grupos orgânicos, embora os mesmos possam ser vulneráveis a fenômenos extremos, em que o elo que fundamenta a relação entre animais e clima é expresso pela equação de balanço energético, além da equação do balanço hídrico (Campbell e Norman, 1998).

Certamente elementos meteorológicos tais como: temperatura, umidade, fluxo de calor no solo e luminosidade configuram condições essenciais para o entendimento e distribuição espacial destes seres vivos nos diversos ecossistemas naturais, inclusive a microfauna (Chapin et al., 2002; Tortora et al., 2004). Estudos realizados em Caxiuanã por Ruivo et al (2002) e Ruivo et al (2007) mostram a influência de fatores ambientais, tais como a temperatura e o $\mathrm{pH}$ do solo na população microbiana e na fauna do solo. Portanto, devem-se levar em conta para estudo, características e condições microclimáticas do solo, especialmente; a variabilidade sazonal do perfil de temperatura em vários níveis, fluxo de calor no solo e a disponibilidade de água no solo, dentre outras.

Este trabalho tem como objetivo, estudar as interações entre o microclima e as populações microbianas de solo sob diferentes condições ambientais, em floresta tropical primaria natural, sendo um deles sob condições normais (PPBio) e o outro sob condição simulada de estresse hídrico (ESECAFLOR). Dessa forma, pretende-se com este estudo avaliar as relações de dependência entre crescimento ou diminuição de populações de microorganismos de solo, associada à componente micrometeorológica, considerando períodos chuvosos, secos e de transição com o intuito de contribuir com estudos sobre este complexo relacionamento entre microrganismos e variações microclimáticas.

\section{MATERIAL E MÉTODOS}

\subsection{Características da área estudada}

A Floresta Nacional de Caxiuanã, local onde estão sendo medidos os dados desse trabalho, fica no município de 
Melgaço (PA), distante cerca de $400 \mathrm{~km}$ de Belém (PA) na região nordeste da Amazônia. Desde 1993 o Museu Paraense Emílio Goeldi mantém em Caxiuanã, em área cedida pelo IBAMA-DF, a Estação Científica "Ferreira Penna" que possui 33 mil hectares $\left(1^{\circ} 42^{\prime} \mathrm{S}, 51^{\circ} 31^{\prime} \mathrm{W}\right)$ correspondentes a $10 \%$ da área total da Floresta Nacional de Caxiuanã." (Figura 1). Nesta reserva, são desenvolvidas pesquisas da fauna, da flora, da climatologia e do homem da região. Pesquisadores de projetos, como o PPBio ESECAFLOR e TEAM, desenvolvem projetos relativos à biodiversidade, variabilidade climática, interação floresta-atmosfera, ciclo do carbono, características do solo, etc.

\subsection{Precipitação}

Para efeito de análise da distribuição sazonal da precipitação em Caxiuanã, foi utilizada a série climatológica da estação pluviométrica do IBAMA, com totais mensais de 28 anos (1980 a 2007). As estações do ano na região amazônica não são bem definidas, devido sua localização em baixa latitude, o que the confere pequena variabilidade anual de alguns elementos meteorológicos como: temperatura do ar, radiação solar global e umidade relativa. O que fica caracterizado neste sentido são

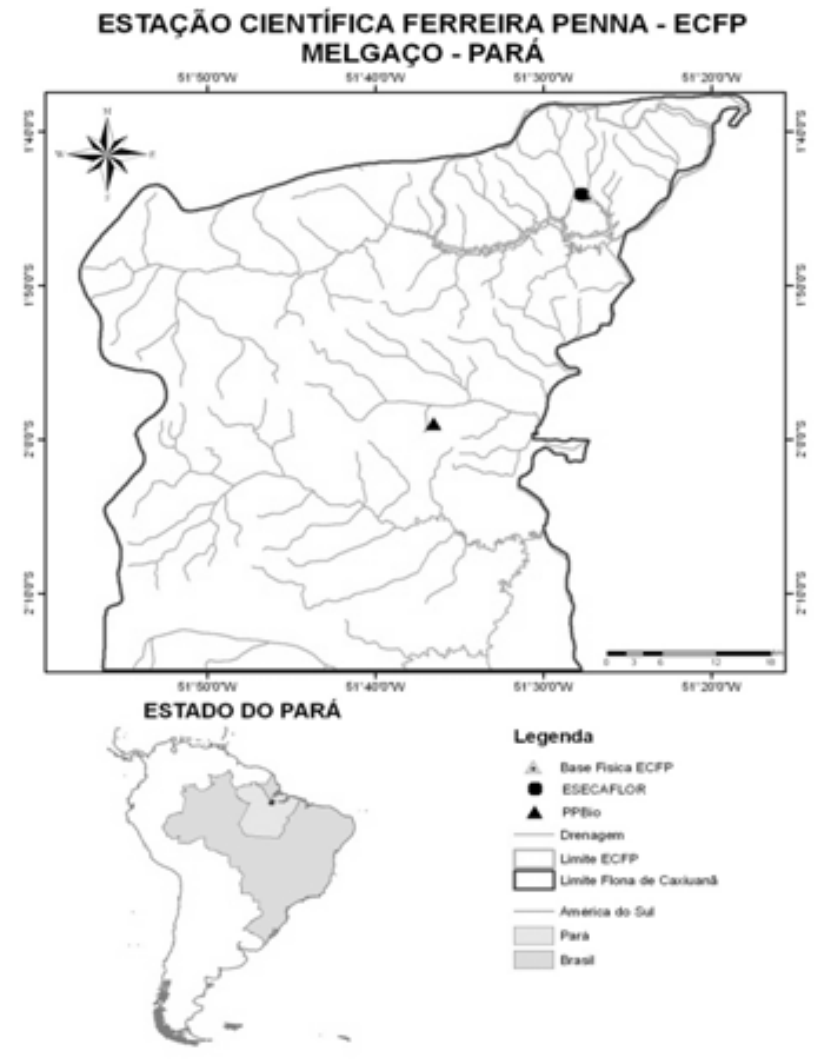

Figura 1- Localização das áreas em estudo. dois períodos distintos, chamados verão e inverno amazônico, que correspondem ao período seco e chuvoso, respectivamente e separados por um período de transição.

De acordo com a Figura 2, climatologicamente, o período chuvoso está compreendido de dezembro a maio, o período de transição de junho a julho e o período seco de agosto a novembro. As coletas de amostragem de solo para análises quantitativas de fungos e bactérias foram feitas em três épocas do ano, correspondentes aos meses de: março, junho e outubro, representativos do período chuvoso, transição e seco, respectivamente.

\subsection{Medições e amostragens}

As medições de variáveis microclimáticas e amostragens de solo foram feitas em dois sítios experimentais, o primeiro em um local denominado parcela "B" do projeto ESECAFLOR (Estudo de Seca na Floresta) que consiste na simulação de um período de seca prolongada para avaliar seu impacto nos fluxos de água e dióxido de carbono em uma área de floresta tropical amazônica, investigando a influência da exclusão de água no solo sobre o ciclo da floresta e as alterações provocadas pelo evento El niño. O segundo sítio está localizado na parte central da grade de abrangência do Programa de Pesquisa em Biodiversidade (PPBio), que visa à criação de um sistema integrado de informação sobre biodiversidade para facilitar a gestão do patrimônio natural do País, assim como, fortalecer ações de pesquisas para o desenvolvimento sustentável da Amazônia.

Os dados de temperatura, foram coletados nas profundidades $5 \mathrm{~cm}, 10 \mathrm{~cm}, 20 \mathrm{~cm}$ e $30 \mathrm{~cm}$, conteúdo volumétrico de água do solo e fluxo de calor no solo entre $0-30 \mathrm{~cm}$, além de medidas de temperatura do ar a $30 \mathrm{~cm}$ da superfície do solo. Estes dados foram coletados por sensores eletrônicos que estão instalados nas duas áreas de abrangência do estudo,

As amostragens de solo foram feitas em três pontos aleatórios ao redor da área onde estavam sendo medidas as variáveis climáticas em cada sítio experimental. Em cada ponto de amostragem foram coletadas quatro amostras de solo referentes às profundidades em que estavam sendo medidas as temperaturas de solo, somando, portanto doze amostras de solo em cada sítio experimental além de uma amostragem com trado a $30 \mathrm{~cm}$ de profundidade para cada época distinta do ano.

O método utilizado para determinar a densidade de fungos e bactérias do solo está baseado na técnica "Pour Plate" descrita por Clark (1965) e comentado por Vieira e Nahas (2000). Os meios de culturas utilizados para promover o crescimento das colônias foram o Agar Padrão (para bactérias) e o Martin (para fungos). O procedimentos para a análise foram realizados no Laboratório de Microbiologia da Universidade do Estado do Pará (UEPA). 


\section{RESULTADOS E DISCUSSÃO}

\subsection{Distribuição da precipitação}

A precipitação total anual medida na reserva de Caxiuanã foi de 2.610,5 mm, enquanto a média climatológica local corresponde a 1.939,6 mm, resultando, portanto em um excedente de $670,9 \mathrm{~mm}$ que correspondeu a um valor maior que a soma de toda precipitação medida nos períodos seco e de transição (Figura 2).

Durante o período experimental, choveu mais do que a média climatológica na época chuvosa, enquanto nas épocas de transição e seca, a precipitação ficou abaixo da média histórica, exceto para o mês de setembro. Vale ressaltar que a estação chuvosa de 2009, estava sob a influência do fenômeno La Nina, iniciado no segundo semestre de 2008. E na época seca do ano de 2009, as condições termais das águas do Pacífico central apontavam para o início de mais um evento de El Niño, que atingiu sua fase madura em dezembro de 2009, influenciando nas reduções de chuvas na Amazônia Oriental. Com isso, a estação chuvosa da área em estudo apresentou totais acumulados de precipitação $48,8 \%$ acima da média e o período seco com $27,5 \%$ abaixo da média. Este cenário irregular de distribuição de precipitação no ano de 2009 tem influência direta sobre o padrão de comportamento de variáveis medidas no solo em diferentes profundidades, que foram correlacionadas com a variabilidade sazonal quantitativa da microfauna de solo.

\subsection{Perfil Fúngico e Bacteriano}

A Figura 3 mostra a variação sazonal da população fúngica no sítios experimentais ESECAFLOR (FE) e PPBio (FP) em diferentes profundidades, e as indicações $\mathbf{1}, \mathbf{2}$ e $\mathbf{3}$ correspondem às épocas chuvosa, transição e seca, respectivamente. As análises microbiológicas mostraram que populações de fungos diminuem com a profundidade em qualquer época do ano e em ambos os sítios experimentais. Nos trabalhos de Martinez e Ramirez (1978) e Goberna et al. (2005) a quantidade de UFC de fungos também declinou conforme o aumento da profundidade; tal comportamento pode ser justificado pela forte correlação que existe entre os microorganismos e a concentração de nutrientes e matéria orgânica do solo. As amostragens de solo feitas a $5 \mathrm{~cm}$ de profundidade para os dois sítios, nas épocas seca e chuvosa, mostraram que as populações de fungos tem maior crescimento no sítio PPBio (área natural), e este padrão se inverte na época de transição, onde se observa maior crescimento no sítio ESECAFLOR (área com exclusão de água). Segundo Pequeno et al. (2002), substâncias ricas em celulose estimulam, principalmente, o crescimento de fungos, podendo então deduzir que na época de transição em ambiente controlado, com sombreamento e baixa disponibilidade hídrica, há mais possibilidade de formação de material rico em celulose que constitui matéria básica para decomposição de fungos.

A variação da população bacteriana (Figura 4), mostra que para o sítio PPBio, a medida que a profundidade aumenta, a população diminui em qualquer época do ano. Todavia para o sítio ESECAFLOR, esta relação não se estabelece, mostrando baixa correlação entre esses dois parâmetros. Este fato permite inferir que em ambiente natural, a maioria das bactérias existentes é do tipo aeróbico, isto é, se proliferam melhor em ambiente onde há maior disponibilidade de oxigênio no solo e em ambiente alterado. O desenvolvimento de bactérias anaeróbicas é maior e tendem a migrar para níveis mais profundos onde há mais umidade no solo modificado, portanto

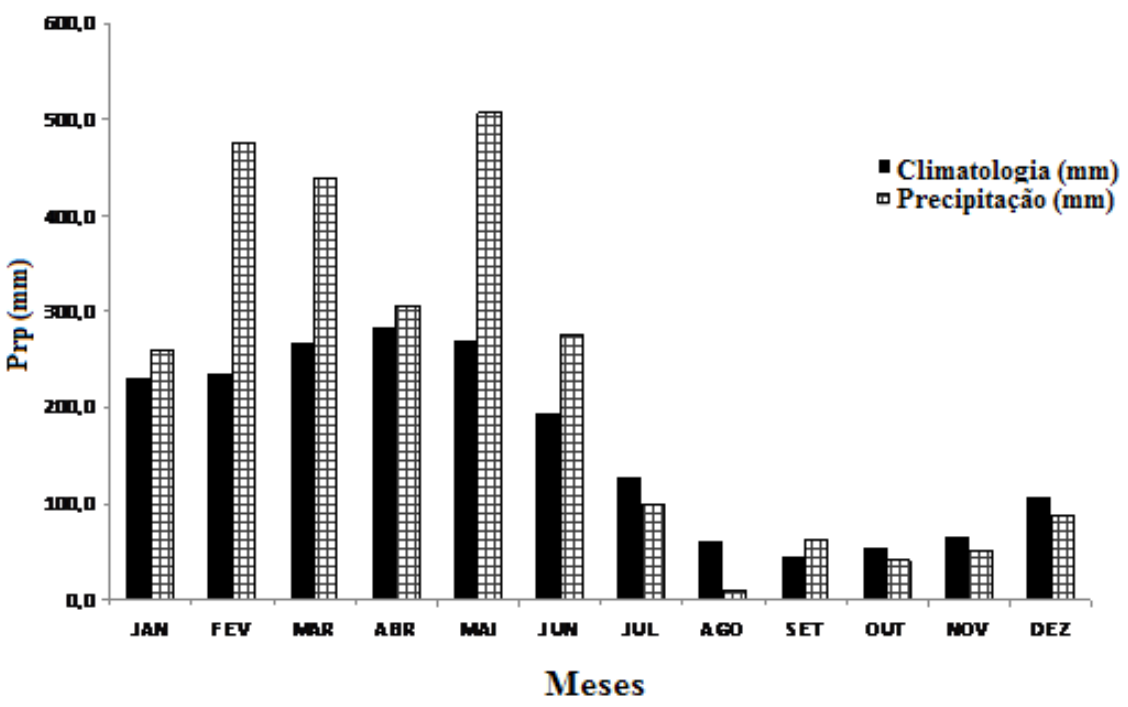

Figura 2- Distribuição da precipitação mensal medida em 2009 e climatologia. 


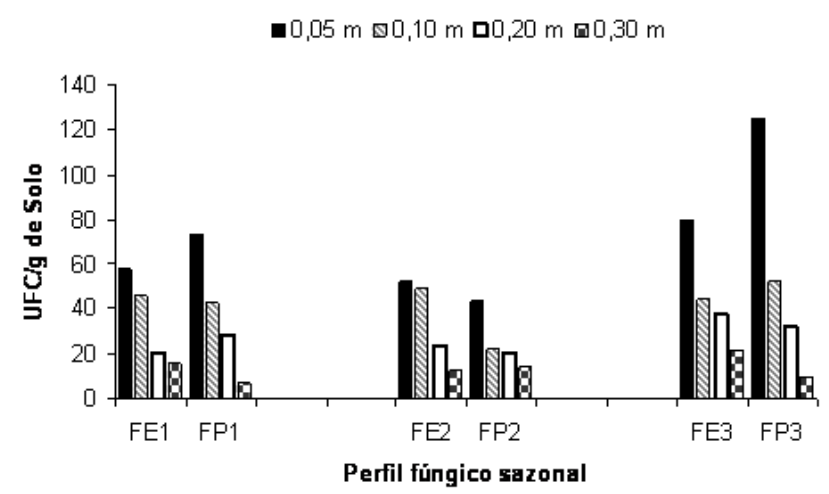

Figura 3 - Variação sazonal da população fúngica para ESECAFLOR e PPBio.

este comportamento pode ser observado na Figura 4 (período seco) onde há mais colônias de bactérias nos dois últimos níveis, do que no nível de $10 \mathrm{~cm}$.

O maior crescimento populacional bacteriano é observado na época chuvosa em ambos os sítios. Tal resultado corrobora com o estudo de Sales et al., 2008, que também comparou a quantidade de UFC de bactérias em diferentes períodos sazonais (seco e chuvoso) e encontrou um número maior de UFC no período chuvoso. Desse modo, comprova-se que a pluviosidade tem participação fundamental no desenvolvimento bacteriano no solo, provavelmente por gerar um micro-ambiente favorável a esses microorganismos. Neste sentido Kennedy e Gewin (1997) dizem que condições ideais de temperatura, umidade e natureza do material em decomposição, favorecem a formação de material rico em proteína (material básico para o desenvolvimento de bactérias), induzindo a dominância deste tipo microbiano.

Em termos quantitativos, comparando as populações de fungos e bactérias, ficou evidenciado que fungos desenvolveram-se melhor na época seca, principalmente em níveis superficiais e bactérias tem sua população mais significativa no período chuvoso. Estes resultados são

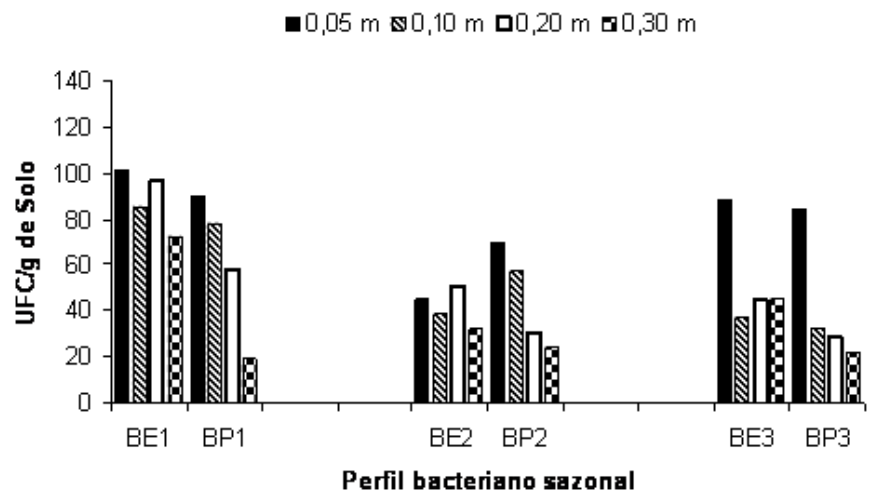

Figura 4 - Variação sazonal da população Bacteriana para ESECAFLOR e PPBio. semelhantes aos encontrados por Ruivo et al. (2002) e Amarante et al (2010), que compararam populações de fungos e bactérias em áreas de Latossolo e Terra Preta Arqueológica na Amazônia, e constatou que populações de bactérias predominam em Latossolo Amarelo na região de Caxiuanã.

\subsection{Relação de dependência com variáveis meteorológicas}

A relação de dependência de populações de fungos e bactérias com medidas de temperatura em diferentes profundidades do solo para o sítio ESECAFLOR é mostrada nas Figuras 5a, 5b e 5c para época chuvosa, transição e seca respectivamente. Para qualquer época analisada, se percebe que a variação da temperatura com a profundidade do solo é mínima, uma vez que este ambiente está constantemente sombreado, ou seja, não há incidência de radiação direta sobre o solo que poderia formar um gradiente de temperatura significativo para diferentes profundidades no solo. Contudo, as análises mostram que a variação ocorrida em populações de bactérias com a profundidade do solo, tem relação direta com variações na temperatura do solo na mesma profundidade, ou seja, para cada pequeno aumento na temperatura, há um ligeiro aumento na população de bactérias e vice-versa.

Conforme Catelan e Vidor (1990) e Souto et al. (2008), as diferentes condições climáticas ocasionadas pelas estações do ano alteram as relações que ocorrem entre o solo e a cobertura vegetal, especialmente nas regiões subtropicais, sendo assim, a atividade microbiana do solo também apresentará flutuação intra-anual, principalmente nos primeiros centímetros onde a umidade e a temperatura são mais sensíveis. Todavia, analisando o comportamento fúngico, percebe-se que esta relação de dependência não se estabelece plenamente, pois pode ser influenciada pelas condições controladas de exclusão de água no solo neste sítio, deduzindo que a população bacteriana parece ser mais sensível às variações de temperatura com a profundidade do solo.

Para o sítio PPBio, onde as medições são feitas em ambiente natural (Figuras 6a, 6b e 6c), as relações de dependência de populações de fungos e bactérias com variações de temperatura no solo se estabeleceram plenamente para qualquer época do ano, evidenciando que em ambiente natural, a variável temperatura influencia diretamente no crescimento ou diminuição de populações destes microorganismo do solo. Com relação a isto, Moreira e Siqueira (2002) ressaltam que quando a temperatura do ambiente está alta as funções metabólicas são alteradas e ocorrem modificações na estrutura das moléculas e no comportamento das enzimas, porém diante de temperaturas baixas, podem ocorrer modificações nos mecanismos de ligação que orientam as estruturas terciárias das proteínas. 


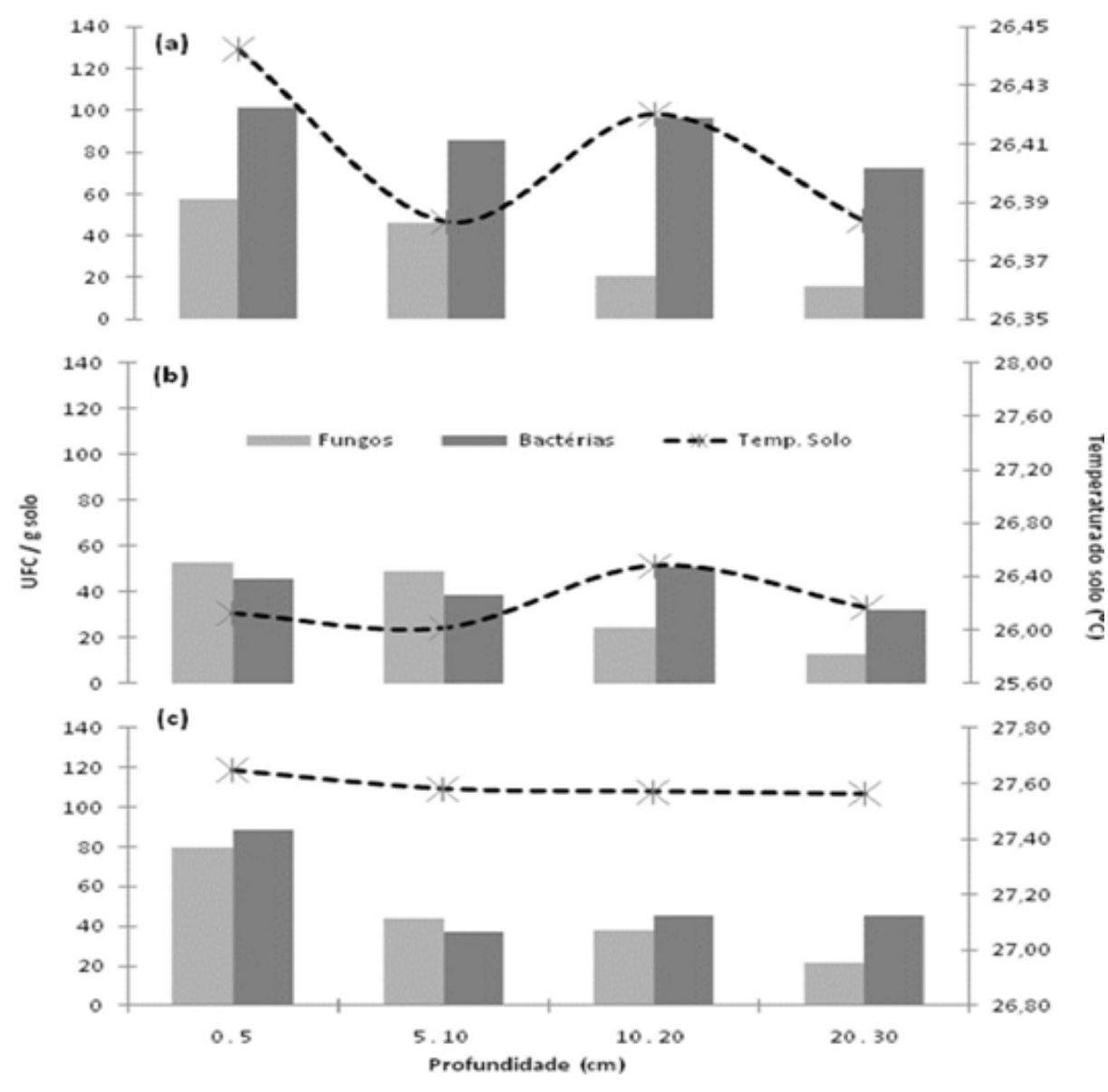

Figura 5- Relação de dependência de populações de fungos e bactérias com temperatura do solo para o sítio ESECAFLOR.

As temperaturas médias obtidas no sítio PPBio, foram sempre menores do que as do sítio ESECAFLOR, porém a variação da temperatura com a profundidade do solo tem o mesmo padrão de comportamento, ou seja, para pequenas variações na temperatura percebe-se variação equivalente nas populações de fungos e bactérias.

As relações da distribuição populacional microbiana, com o conteúdo volumétrico de água no solo (CVAS) em escala sazonal para os sítios ESECAFLOR e PPBio podem ser visualizadas nas Figuras 7 e 8, respectivamente. No sítio ESECAFLOR, caracterizado pela exclusão de água no solo, a amplitude sazonal do CVAS é pequena, com picos máximos de $10 \mathrm{~m}^{3} \mathrm{~m}^{-3}$ na época chuvosa e $6 \mathrm{~m}^{3} \mathrm{~m}^{-3}$ na época seca. Contudo, percebe-se que variações no teor de água no solo, influenciam diretamente a proporção de fungos e bactérias no solo, ou seja, à medida que se diminui o volume de água no solo, tende a diminuir as populações de bactérias e aumentar as populações de fungos, que auxiliam na decomposição de matéria orgânica do solo e vice-versa.
$\mathrm{Na}$ área do sítio PPBio, caracterizada por ambiente de floresta densa natural, foram encontrados, como esperado, valores maiores de conteúdo volumétrico de água no solo com picos máximos e mínimos de $38 \mathrm{~m}^{3} \mathrm{~m}^{-3}$ e $24 \mathrm{~m}^{3} \mathrm{~m}^{-3}$ respectivamente. Porém, de uma forma geral o comportamento sazonal das populações de fungos e bactérias, com relação às variações no conteúdo volumétrico de água no solo, é proporcionalmente similar ao encontrado no sítio ESECAFLOR. Souto et al. (2008) estudando a redução do conteúdo de água no solo, observou que no período de estiagem a população fúngica sofreu decréscimos e quando havia eventos de precipitação fora da época o conteúdo de água no solo alcançava uma total de até $10 \%$, e o aumento da população fúngica era favorecido. Porém, nos meses (janeiro e fevereiro) onde foram obtidos os registros de maiores precipitações os decréscimos, foram mais intensos, indicando que a umidade do solo regula as flutuações da população de fungos, uma vez que os extremos limitam o desenvolvimento dos microorganismos. O trabalho de Catelan e Vidor (1990) 


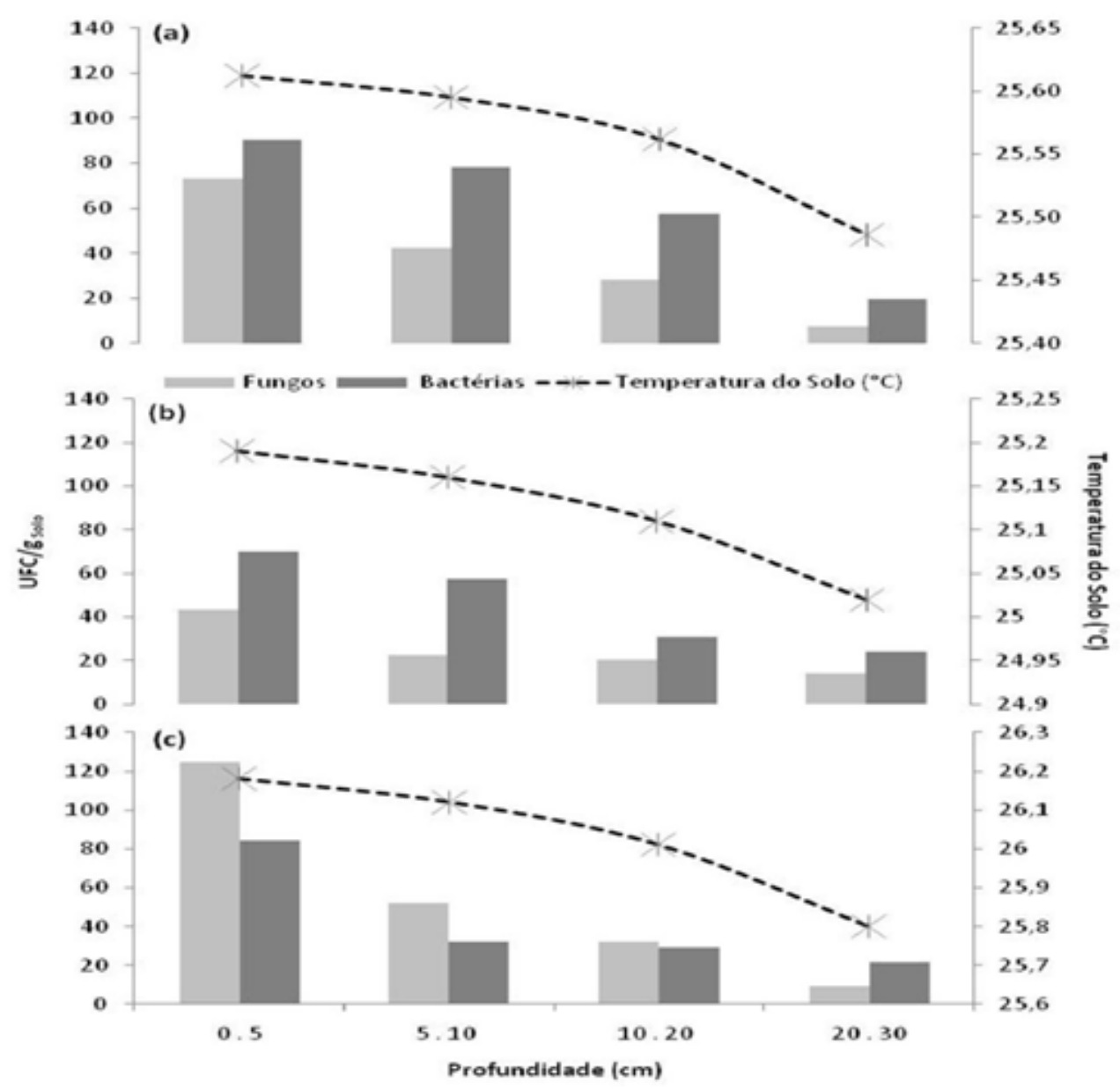

Figura 6 - Relação de dependência de populações de fungos e bactérias com temperatura do solo para o sítio PPBio.

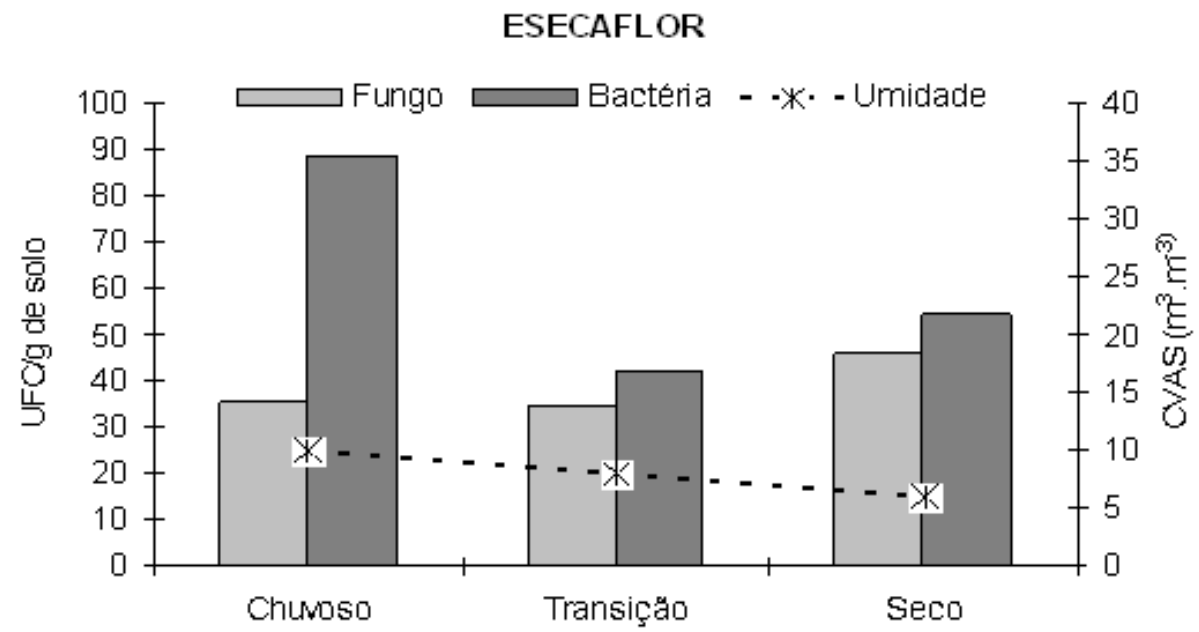

Figura 7- Relação de dependência de populações de fungos e bactérias com conteúdo volumétrico de água no solo para o sítio ESECAFLOR. 


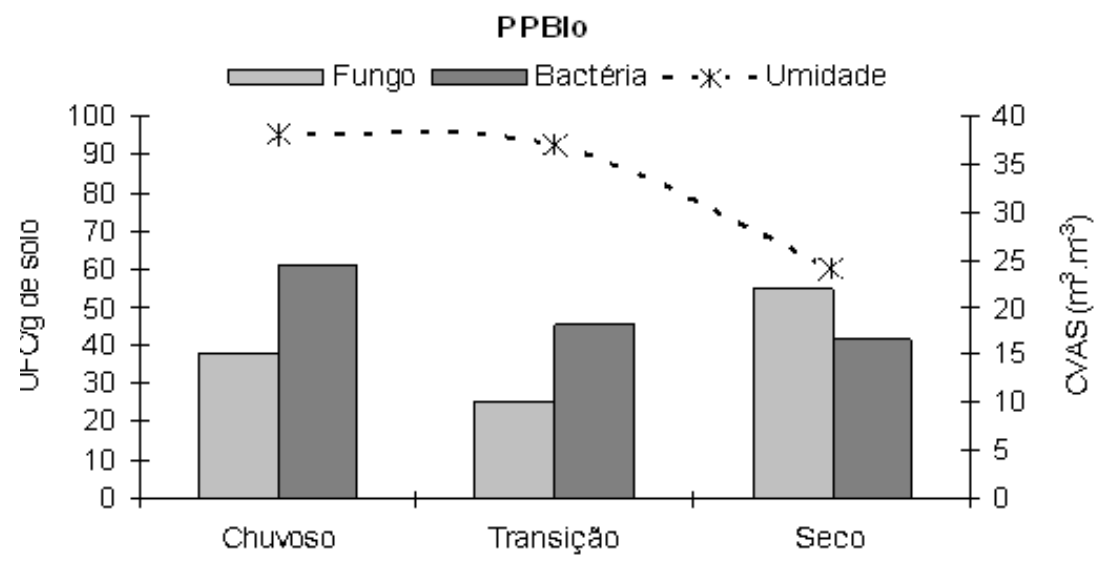

Figura 8 - Relação de dependência de populações de fungos e bactérias com conteúdo volumétrico de água no solo para o sítio PPBio.

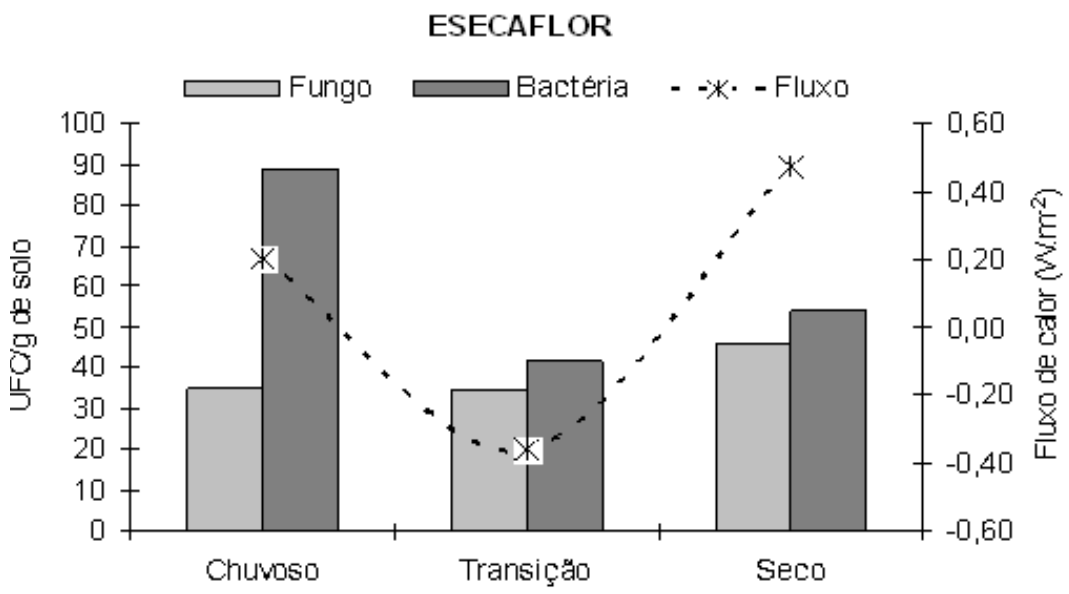

Figura 9 - Relação de dependência de populações de fungos e bactérias com fluxo de calor no solo para o sítio ESECAFLOR.

demonstrou que os fungos também apresentam comportamento diferente sob condições de umidade baixa em diferentes sistemas de cultura.A relação de fluxo de calor no solo com variações nas populações de microorganismos de solo pode ser visualizada nas Figura 9 (sítio ESECAFLOR) e Figura 10 (sítio PPBio). De uma forma inversa ao teor de água no solo, o fluxo de calor deste é maior no período seco e menor no período chuvoso, com isso, com o aumento de fluxo de calor no solo se observa um respectivo aumento nas populações de fungos, e conseqüente diminuição nas populações de bactérias.

No sítio ESECAFLOR o fluxo médio diário é negativo no período de transição, indicando que há maior transporte de calor no sentido de níveis mais profundos do solo em direção a superfície que se resfria por perdas radiativas de ondas longas. Para as épocas seca e chuvosa esse transporte dá-se no sentido inverso, ou seja, da superfície para níveis mais profundos. Isso ocorreu mesmo no período chuvoso, pois este sítio, que tem sua área coberta, a chuva não tem influência significativa sobre o transporte de calor no solo.

Este fato não é comum em uma área de floresta natural em período chuvoso (Figura 10) que apresenta valores médios diários negativos, indicando que em média há mais transporte no sentido de níveis mais profundos em direção a superfície, e somente no período seco é que se observa esse transporte no sentido inverso.

\section{CONCLUSÕES}

O padrão de distribuição de populações de fungos diminui com a profundidade em ambos os sítios experimentais em qualquer época do ano. Populações de bactérias apresentam este padrão apenas no sítio natural (PPBio). No sítio com exclusão de água (ESECAFLOR) este comportamento é irregular.

Com relação à distribuição quantitativa de fungos e bactérias com a sazonalidade em latossolo amarelo, pode-se 


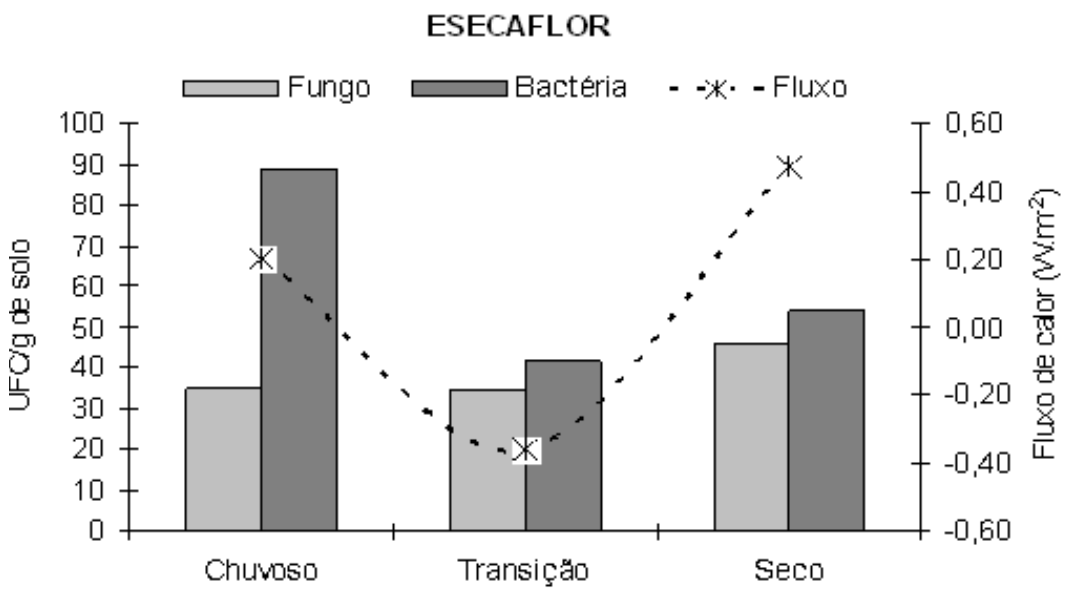

Figura 10 - Relação de dependência de populações de fungos e bactérias com fluxo de calor no solo para o sítio PPBio.

observar que populações de fungos desenvolveram-se melhor em época seca e bactérias em época chuvosa.

Populações de bactérias apresentaram a melhor relação de dependência com a variável temperatura para diferentes profundidades.

Variações no teor de água no solo influenciaram diretamente a proporção de fungos e bactérias, ou seja, ao aumentar o volume de água no solo, aumenta a população de bactérias e diminui a população de fungos.

Populações de fungos desenvolveram-se mais em época seca devido a maiores taxas de fluxo de calor observadas neste período e as bactérias, por sua vez, desenvolveram-se melhor em épocas chuvosa e de transição.

\section{AGRADECIMENTOS}

Os autores agradecem ao $\mathrm{MCT} / \mathrm{CNPq} /$ Universal que financiaram este projeto, ao programa PPBio e projeto LBA/ ESECAFLOR, ao Projeto CNPQ/FAPESPA/UFPA Pronex -Mudanças Climáticas e a todos que participaram da instalação e coleta de dados no campo.

\section{REFERÊNCIAS BIBLIOGRÁFICAS}

AMARANTES, C. B. ; RUIVO, MLP ; OLIVEIRA, M. L. ; MOURA, Q. L. Diversidade Microbiana em solos de Terra Preta Arqueológica. Enciclopédia biosfera, v. 6, n. 11, p. 1-10, 2010.

CAMPBELL, G. S.; NORMAN, J. M. An Introduction to Environmental Physics. Springer, N. York, 286 p., 1998.

CATELAN, A. J.; VIDOR, C. Flutuações na biomassa, atividade e população microbiana do solo, em função de variações ambientais. Revista Brasileira de Ciência do Solo, Campinas, v. 14, n. 2, p. 133-142, 1990.
CHAPIN, F. S.; MATSON, P. A.; MOONEY, H. A. Principles of terrestrial Ecosystem ecology. Nova York: Springer, 2002, 455 p.

CLARK, F.E. Agar-plate method for total microbial count. In: BLACK, C.A.; EVANS, D.D.; ENSMINGER, L.E.; WHITE, J.L.; CLARK, F.E. Methods of soil analysis. Madison: American Society of Agronomy, 1965. v.2, p.1460-1466.

DE-POLLI, H; GUERRA, J. G. M. Carbono, nitrogênio e fósforo na biomassa microbiana do solo. UFRS: Porto Alegre, 1999, 508p. .

KENNEDY, A.C.; GEWIN, V.L. Soil microbial diversity: present and future considerations. Soil Science, v.162, p.607-617, 1997.

GOBERNA, M. et al. Microbial community structure at different depths in disturbed and undisturbed semiarid Mediterranean forest soil. Microbial Ecology. v. 5, n. 40, p. 315- 326, 2005.

MARTINEZ, A. T.; RAMIREZ, C. Microfungal biomass and number of propagules in an andosol. Soil Biology and Biochemistry. v. 10, n. 6, p. 529-531, 1978.

MOREIRA, F.; SIQUEIRA, J. O. Microbiologia e Bioquímica do Solo. UFLA: Larvas, 2002. 623 p.

PEQUENO, P. L. L. et al. Aspectos sobre a matéria orgânica do solo. Artigos 2002. Disponível em: http://www.arvore. com.br/artigos/htm_2002/ar2308_2.htm.

RUIVO, M.L.P; et al. LBA - Esecaflor artificilly induced drought in Caxuanã Reserve, East Amazonia: soil propriertes and litter spider fauna. Earth Interections. v.11 n.8 p.1 13, 2007.

RUIVO, M. L. P. et al. Propriedades do solo e fluxo de CO2 em Caxiuanã, Pará: experimento LBA- Esecaflor. In: KLEIN, E.L.; VASQUEZ, M.L.; ROSA-COSTA, M.L. (Orgs.) Contribuições à Geologia da Amazônia, V.3. SBG-Núcleo Norte, 2002, p. 291-299. 
SALES, T. M. et al. Diversidade de bactérias de solo em clareiras e floresta nativa provenientes de áreas de terra firme alteradas pela exploração de petróleo. In: SEMINÁRIO DE INICIAÇÃO CIENTÍFICA DA EMBRAPA AMAZÔNIA ORIENTAL, 12, 2008, Belém. Anais... Belém: Embrapa, 2008.

SOUTO, P C. et al. Comunidade microbiana e mesofauna edáficas em solo sob Caatinga no semi-árido da Paraíba. Revista Brasileira de Ciências do Solo, v. 32, p. 151-160, 2008.
TORTORA, G. J.; FUNKE, B. R.; CASE, C. L. Microbiology: an introduction. E. Pearson, 8 ed., 2004.

VIEIRA, F C S; NAHAS, E. Quantificação de bactérias totais e esporuladas no solo. Scientia Agricola, v.57, n.3, p.539$545,2000$.

WARDLE, D. A.; HUNGRIA, M. A biomassa microbiana do solo e sua importância nos ecossistemas terrestres. In: Microorganismos de importância agrícola. Brasília: EMBRAPA, 1994, 226p. 